Section Editor

Robert C. Griggs, MD
Editors' Note: In response to the paradoxes in the study "Do-not-resuscitate orders, quality of care, and outcomes in veterans with acute ischemic stroke" pointed out by Dr. Bernat, Dr. Reeves et al. question the uniformity of care in the Veterans Health Administration (VHA). Referencing the Neuro/mage by Dr. Scully et al., Dr. Nandigam explains and discusses different enhanced susceptibility imaging (ESI) techniques and how licensing and patent issues force different MRI vendors to modify, slightly, a particular sequence technique to avoid infringement. Dr. Scully et al. agree and stress that ESI should replace T2*-gradient echo sequence (GRE).

Chafic Karam, MD, and Robert C. Griggs, $M D$

\section{DO-NOT-RESUSCITATE ORDERS, QUALITY OF CARE, AND OUTCOMES IN VETERANS WITH ACUTE ISCHEMIC STROKE}

James L. Bernat, Lebanon, NH: Reeves et al. ${ }^{1}$ showed that the presence of a do-not-resuscitate (DNR) order in patients with ischemic stroke within Department of Veterans Affairs (DVA) hospitals did not affect most of their surrogate quality indicators. I agree with the authors' interpretation that the DVA physicians used DNR orders appropriately and, unlike some physicians, did not misinterpret them as orders to limit therapy. The reasons for the authors' findings are worthy of consideration. The standardization of clinical practices within the DVA health system-a top-down, closed, health maintenance organization model, uniformly regulated health care system-may account for the consistency of surrogate quality indicators in the hospitalized patients. But if standardization of practice is the explanation, why is there still such a vast difference in rates of DNR orders for ischemic stroke patients among DVA hospitals? And why are there global deficiencies in other stroke care surrogate quality indicators such as dysphagia screening and stroke education? I conclude that the extent of standardization of best stroke care practices within DVA hospitals is great enough to include the proper interpretation of DNR orders but not high enough to encompass all best practices for stroke care.
WriteClick: Editor's Choice

Author Response: Mathew J. Reeves, East Lansing, MI; Laura Myers, Linda Williams, Indianapolis; Michael Phipps, New Haven, CT; Dawn Bravata, Indianapolis: We thank Dr. Bernat for his interest in our report, and particularly for highlighting some of the paradoxes in our findings. DVA physicians were not inappropriately interpreting DNR orders to limit basic aspects of stroke care, which reflects positively on the VHA. However, we do not believe that this is because the VHA represents a top-down, uniform health care system. Before November 2011, the VHA had done little to create a system that promoted high-quality organized stroke care, and few standardized stroke care practices existed in 2007 when our reports were collected. This lack of standardization is also reflected in several care processes that fell short of acceptable benchmarks: thrombolysis treatment, dysphagia screening, NIH Stroke Scale documentation, and stroke education. Dr. Bernat correctly highlighted the need to better understand the substantial variability in documentation of DNR orders across Veterans Affairs facilities (range $0 \%$ to $79 \%$ ). This level of variability is especially hard to understand given that an electronic DNR order was available throughout the VHA system. We are currently exploring the contributions of differences in case mix, case load, and other facility characteristics on this variability, and whether this had any bearing on quality of care and patient outcomes.

\section{(C) 2013 American Academy of Neurology}

1. Reeves MJ, Myers LJ, Williams LS, Phipps MS, Bravata DM. Do-not-resuscitate orders, quality of care, and outcomes in veterans with acute ischemic stroke. Neurology 2012;79: 1990-1996.

\section{SWAN MRI REVEALING MULTIPLE MICROHEMORRHAGES SECONDARY TO SEPTIC EMBOLI FROM MUCORMYCOSIS}

Kaveer Nandigam, Amherst, NY: The NeuroImage by Scully et al. ${ }^{1}$ attempted to show that the new T2* susceptibility-weighted angiography (SWAN) MRI is more sensitive to show microbleeds not visualized on T2*-GRE. SWAN MRI may not be a familiar term to all neurologists. ESI techniques have recently gained 
popularity for being more sensitive in showing paramagnetic tissues compared with the standard T2* GRE. This was initially commercialized as susceptibility-weighted imaging (SWI) by Siemens (Malvern, PA) MRI. SWI uses additional phase information to increase the sensitivity. ${ }^{2}$ We previously reported evidence for higher sensitivity of SWI over GRE. ${ }^{3}$ Since then, it is gradually replacing T2*-GRE in clinical imaging, especially in settings where Siemens MRI is used. Due to licensing and patent issues, different MRI vendors are often forced to slightly modify a sequence technique to avoid infringement. To provide an equivalent ESI technique, General Electric (Milwaukee, WI) modified the T2*-GRE by multiecho acquisition and postprocessing reconstruction as weighted average in its MRI and called it SWAN. Similarly, Philips (Andover, MA) MRI uses a different postprocessing technique called phase difference enhanced imaging (PADRE) to combine the phase information. The different ESI are probably superior to T2*-GRE. It would be interesting to compare ESI techniques from different vendors, comparing apples to apples.
Author Response: Michele A. Scully, Rochester, NY: We appreciate Dr. Nandigam's further explanation about ESI techniques and clarification that-like a number of other MRI methods - they are identified and performed differently by different MRI vendors. Neurologists should be aware of the variety of MRIenhanced susceptibility sequence names and that each is performed in slightly different ways. We concur with Dr. Nandigam that ESI should replace T2*-GRE and that various techniques used by the different MRI vendors for specialized MRI sequences should be rigorously compared.

(C) 2013 American Academy of Neurology

1. Scully MA, Yeaney GA, Compton ML, Berg MJ. SWAN MRI revealing multiple microhemorrhages secondary to septic emboli from mucormycosis. Neurology 2012;79: 1932-1933.

2. Haacke EM, Mittal S, Wu Z, Neelavalli J, Cheng YC. Susceptibility-weighted imaging: technical aspects and clinical applications, part 1. AJNR Am J Neuroradiol 2009;30:19-30.

3. Nandigam RN, Viswanathan A, Delgado P, et al. MR imaging detection of cerebral microbleeds: effect of susceptibilityweighted imaging, section thickness, and field strength. AJNR Am J Neuroradiol 2009;30:338-343.

\section{CORRECTION}

\section{Management of carotid stenosis in women: Consensus document}

In the article "Management of carotid stenosis in women: Consensus document" by P. De Rango et al. (Neurology 2013;80:2258-2268), there is an error in the author list. The third author's name should read Didier Leys, MD, PhD.

The authors regret the error. 


\section{Neurology}

\section{SWAN MRI revealing multiple microhemorrhages secondary to septic emboli from}

mucormycosis

Kaveer Nandigam and Michele A. Scully

Neurology 2013;81;199-200

DOI 10.1212/01.wnl.0000432237.13307.12

\section{This information is current as of July 8, 2013}

\section{Updated Information \&} Services

References

Permissions \& Licensing

Reprints including high resolution figures, can be found at: http://n.neurology.org/content/81/2/199.2.full

This article cites 3 articles, 3 of which you can access for free at: http://n.neurology.org/content/81/2/199.2.full\#ref-list-1

Information about reproducing this article in parts (figures,tables) or in its entirety can be found online at:

http://www.neurology.org/about/about_the_journal\#permissions

Information about ordering reprints can be found online: http://n.neurology.org/subscribers/advertise

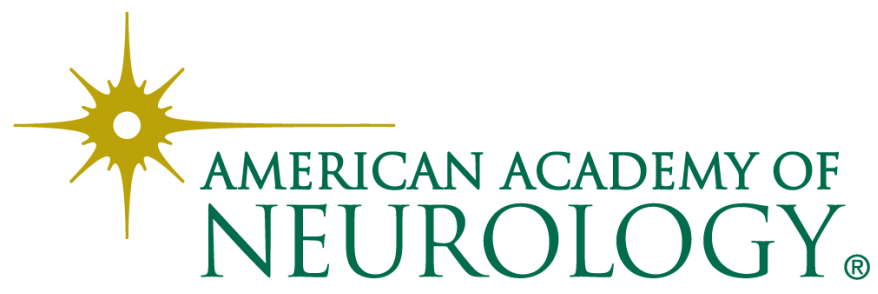

